
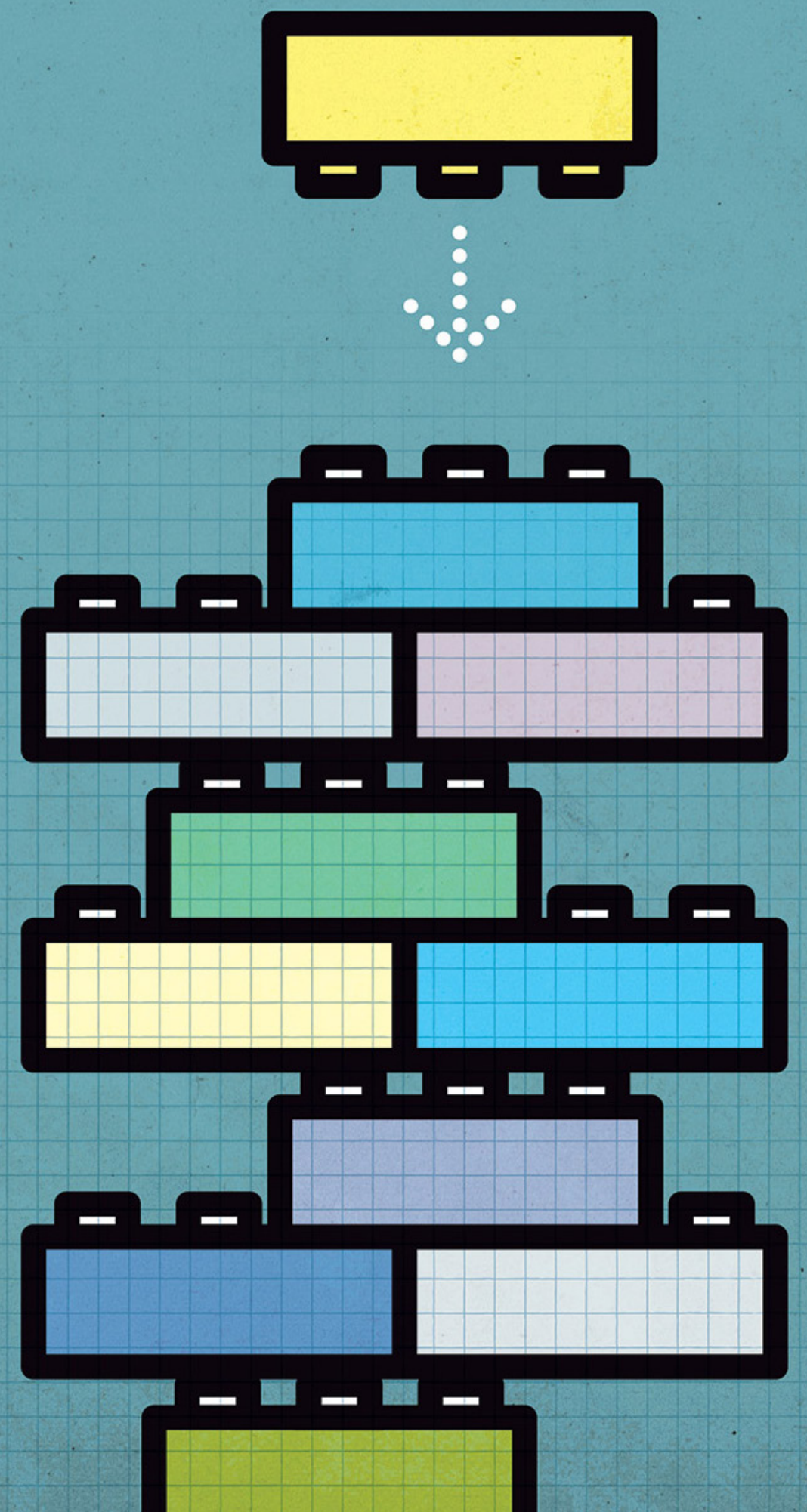


\title{
A trajetória histórica da construção da capacidade tributária brasileira
}

\author{
The historical construction of Brozilion fiscal \\ corpacity
}

Roberta Rodrigues Marques da Silva*

\begin{abstract}
Resumo
Buscamos identificar as principais mudanças observadas na trajetória da extração tributária no Brasil. Argumentamos que a ampliação da capacidade de extração tributária, acompanhada por sua complexidade e sua regressividade, resultou de escolhas feitas pelos governos diante das conjunturas críticas abertas nos diferentes estágios da construção da trajetória institucional. As características atuais da carga tributária brasileira resultam de decisões governamentais que visavam ampliar a capacidade tributária, ao mesmo tempo em que buscavam acomodar as demandas pelo estabelecimento de políticas públicas de caráter desenvolvimentista, por meio da proliferação de impostos e contribuições, sem atenção ao seu caráter regressivo.
\end{abstract}

Palavras-chave: capacidades estatais; capacidade tributária; conflito distributivo.

\begin{abstract}
We seek to identify the main changes observed in the trajectory of tax extraction in Brazil. We argue that the expansion of tax extraction capacity, accompanied by its complexity and its regressivity, resulted from choices made by governments in the face of the critical conjunctures open at the different stages of the construction of the institutional trajectory. The current characteristics of the Brazilian tax burden are the result of governmental decisions aimed at increasing tax capacity, while at the same time seeking to accommodate the demands for the establishment of developmental public policies, through the proliferation of taxes and contributions, without attention to their character regressive.
\end{abstract}

Keywords: state capabilities; tax capacity; distributive conflict.

\footnotetext{
* Professora Adjunta do Departamento de Ciência Política da Universidade Federal Fluminense.

E-mail: Roberta.rodriguez@id.uff.br.
} 


\section{INTRODUÇÃO}

O sistema tributário brasileiro é caracterizado por sua carga impositiva relativamente elevada, sua complexidade e regressividade. Trata-se de um dos únicos países na América Latina onde a carga tributária ultrapassa $30 \%$ do PIB ${ }^{1}$. O Brasil possui, ademais, uma multiplicidade de impostos e contribuições sociais - muitas de incidência cumulativa ou "em cascata" -, diferentes regras para concessão de isenções tributárias (Mancuso; Gonçalves \& Mencarini, 2010) e um importante imposto estadual - o ICMS - cujas alíquotas variam conforme a jurisdição onde é cobrado. Essas características tornam o sistema tributário brasileiro bastante complexo, levando-o a se tornar alvo de constantes críticas por parte de organizações representativas dos setores produtivos e de serviços. Estes atores consideram a complexidade da carga impositiva um fator relevante no chamado "custo Brasil", responsável por dificultar a realização de negócios e por comprometer a eficiência da produção nacional (Azevedo \& Melo, 1997). Trata-se, ainda, de um sistema tributário regressivo, muito centrado no consumo, que onera as famílias de forma inversamente proporcional à sua renda (Pochmann, 2008), o que tem sido objeto de questionamento por parte de setores da sociedade civil de caráter progressista.

Neste artigo, buscamos identificar as principais mudanças observadas na trajetória da extração tributária no Brasil. Argumentamos que a ampliação da capacidade de extração tributária, acompanhada por sua complexidade e sua regressividade, resultou de escolhas feitas pelos governos diante das conjunturas críticas abertas nos diferentes estágios da construção da trajetória institucional. Nesse sentido, as características atuais da carga tributária brasileira resultam de decisões governamentais que visavam ampliar a capacidade tributária do Estado Brasileiro, ao mesmo tempo em que buscavam acomodar as demandas pelo estabelecimento de políticas públicas de caráter desenvolvimentista - ora voltadas para o fomento à industrialização, ora com foco na ampliação dos gastos sociais - por meio da criação de fontes de receita tributária que redundaram na proliferação de impostos e contribuições, sem atenção ao seu caráter regressivo.

Como pode ser observado no gráfico abaixo, a ampliação da capacidade tributária no Brasil ocorreu em dois momentos específicos da trajetória: (i) a partir da reforma tributária de 1966, durante o Regime Militar, que pretendia implementar um sistema impositivo funcional às estratégias de desenvolvimento econômico; (ii) a partir da homologação da Constituição de 1988, quando foi instituído um orçamento voltado para a garantia dos direitos associados à seguridade social.

As instituições que regem a tributação são 'dependentes da trajetória' (path dependent) (Melo, 2005), isto é, as mudanças institucionais são difíceis e condicionadas por acontecimentos históricos contingentes (Pierson, 2004; Mahoney, 2000). A'dependência de trajetória' implica na existência de processos autorreforçáveis, mecanismos de 'reforço positivo' (positive feedback) ou de 'aprisionamento' (lock-in), que garantem 
e estabilidade institucional e, consequentemente, tornam a mudança institucional muito difícil (Mahoney, 2000; Pierson, 2004).

Afirmar que as mudanças na estrutura tributária são difíceis, porém, não implica na defesa da sua impossibilidade (Crouch \& Farrell, 2002). Por um lado, mudanças institucionais podem ocorrer em resposta a choques exógenos ou conjunturas críticas, entendidas com "períodos de contingência durante os quais restrições usuais sobre a ação são retiradas ou aliviadas", permitindo maior espaço para a agência em relação à estrutura e, portanto, à reconfiguração desta (Mahoney \&Thelen, 2010, p.07. Tradução nossa). Por outro lado, mudanças incrementais também são possíveis, e derivam de processos de articulação de coalizões que contestam as interpretações dominantes sobre as normas institucionais, propondo - e disputando - a definição de uma nova interpretação. Qualquer que seja o tipo de mudança, importa frisar que as instituições têm impacto sobre o conflito distributivo e, portanto, são objeto da preocupação (e da ação) dos atores interessados (Mahoney \& Thelen, 2010).

Nessa linha, argumentamos que as reformas tributárias no Brasil ocorreram nos momentos de mudança de regime político, que permitiram a abertura de conjunturas críticas, forjando as condições propícias à emergência de coalizões reformistas (Arretche, 2005). Em última análise, essas coalizões foram capazes de introduzir mudanças na legislação tributária e na organização da burocracia pública (Receita Federal) que fortaleceram a capacidade de arrecadação por parte do Estado Brasileiro. Conforme a literatura sobre Estado e tributação (Levi, 1988; Tilly, 1990), entendemos que a capacidade tributária do Estado significa, simplesmente, a extração de recursos tributários para a organização dos gastos seus militares e administrativos². Essa 'dependência de trajetória' tem dificultado a aprovação de reformas tributárias durante a Nova República (Melo, 2005)³, não obstante as demandas dos atores societais, embora mudanças incrementais na estrutura tributária tenham ocorrido pelos diferentes governos do período ${ }^{4}$.

Gráfico 1: Carga Tributária (Tributação/PIB) - Brasil - 1947-2011

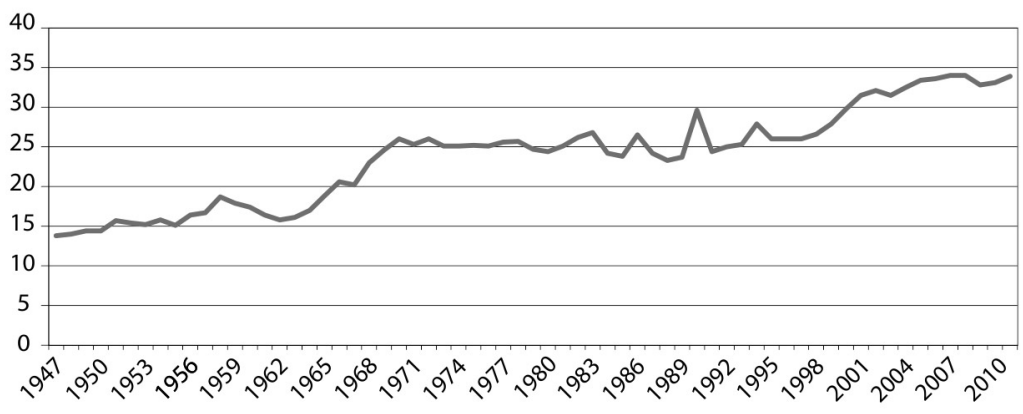


Compreender o aumento da capacidade de extração tributária do Estado Brasileiro importa para a própria agenda de pesquisa sobre capacidades estatais no país: na literatura, a capacidade tributária é tomada como condição sine qua non para viabilizar as demais capacidades estatais (Levi, 1988; Tilly, 1990; Centeno, 2002). Em outras palavras, trata-se da capacidade estatal mais fundamental, haja vista que é indispensável para a promoção de políticas públicas. A análise, ademais, tangencia uma questão importante no debate sobre política distributiva e justiça social: a questão da regressividade da carga tributária brasileira, colocada em segundo plano frente às iniciativas voltadas, particularmente no marco da Constituição Federal de 1988, de promoção da redistribuição por via das despesas, com a previsão da ampliação do arcabouço garantidor dos direitos sociais (Fadiño \& Kerstenetzky, 2019; Maciel, 2019).

No que segue, o artigo está organizado em cinco seções. Nas duas primeiras, discutimos a literatura sobre capacidades estatais e seu papel na promoção de agendas de desenvolvimento, além de nos ocuparmos da revisão da literatura sobre capacidade tributária. Nas três seções seguintes, voltamo-nos para as principais mudanças na tributação ocorridas no contexto das estratégias de desenvolvimento adotadas desde a Primeira República até o período da Assembleia Constituinte de 1987-88. Desta forma, pretendemos identificar as conjunturas críticas que levaram à construção e subsequentes modificações do sistema tributário brasileiro, tornando-o elevado, complexo e regressivo. Considerações finais encerram o artigo.

\section{CAPACIDADES ESTATAIS PARA O DESENVOLVIMENTO}

A análise da capacidade tributária no Brasil está intimamente relacionada à discussão mais geral sobre capacidades estatais. Embora se faça presente na literatura desde a década de 1980, o tema ainda suscita controvérsias em torno de questões importantes: o que são capacidades estatais? Como as capacidades estatais importam para a promoção do desenvolvimento? Quais aspectos determinam as capacidades estatais (Skocpol, 1985)?

A literatura tem destacado a importância do Estado enquanto ator que age de forma mais ou menos autônoma frente à sociedade civil, exercendo impacto, por si mesmo, na elaboração e execução de políticas públicas. Não apenas os atores societais são dotados de interesses próprios; o Estado também o é. O Estado também é entendido enquanto instituição, sendo capaz de limitar as opções disponíveis aos atores societais na seleção de alternativas políticas (Skocpol, 1985; Geddes, 1994; Boschi, 2012; Enriquez \& Centeno, 2012). Nesse sentido, o Estado se constitui, ao mesmo tempo, enquanto espaço de disputas de interesses entre coalizões e ator interessado no conflito distributivo, capaz de alocar recursos de acordo com a agenda pública estabelecida (Boschi \& Gaitán, 2016).

Segundo Skocpol, o Estado apresenta duas características centrais e estreitamente relacionadas, que são fundamentais para a promoção do desenvolvimento: a 
autonomia estatal e as capacidades estatais. A autonomia estatal é entendida como a "formulação e busca de objetivos [pelos Estados] que não são apenas reflexos das demandas ou interesses dos grupos sociais, classes ou sociedade." (Skocpol, 1985, p.09. Tradução nossa). As capacidades estatais, por sua vez, estão relacionadas "à implementação de objetivos públicos, especialmente sobre a oposição real ou potencial de grupos sociais poderosos ou em face de circunstâncias socioeconômicas recalcitrantes." (Skocpol, 1985, p.09. Tradução nossa).

Scokpol ressalta a dimensão sociopolítica associada à noção de capacidades estatais. Esta não é, entretanto, a única enfatizada pela literatura a respeito das capacidades estatais, as quais podem incluir, ainda, aspectos "coercitiv[os], fisca[ais], administrativ[os], relaciona[is] [e] lega[is]" (Gomide, 2016, p.23). Os diferentes atributos das capacidades estatais estão relacionados. Sustentamos que os processos políticos adquirem centralidade na construção das demais capacidades estatais (Geddes, 1994), incluindo a capacidade tributária.

As capacidades estatais são indispensáveis para a formação de consensos políticos que permitam a definição de uma agenda desenvolvimentista, bem como para a implementação mesma das políticas constantes na agenda ${ }^{5}$ (Boschi, 2012). Segundo Enríquez e Centeno, o Estado Desenvolvimentista desempenha papel central na "coordenação e [na provisão dos] recursos necessários para decretar melhorias generalizadas na qualidade de vida e no crescimento econômico sustentado." (Enriquez \& Centeno, 2012 p.132. Tradução nossa). O desenvolvimento é entendido, assim, como o processo que leva à transformação da cadeia produtiva e à inclusão social. Trata-se, pois, de "um processo de ordem interna estreitamente ligado ao surgimento e à consolidação de Estados com capacidades de intervir na economia e na sociedade." (Boschi \& Gaitán, 2016, p.510). Cumpre destacar que o Estado é lócus de poder, sendo capaz de implementar determinadas políticas mesmo diante da oposição de grupos de interesse fortes (Skocpol, 1985; Geddes, 1994; Weaver \& Rockman apud Boschi, 2012).

Na próxima seção, voltamo-nos mais atentamente para a discussão sobre a capacidade tributária dos Estados, central para a compreensão das capacidades estatais em outras áreas da agenda pública ${ }^{6}$.

\section{CAPACIDADE TRIBUTÁRIA E DESENVOLVIMENTO}

Em trabalho seminal, Tilly identifica os processos de formação dos Estados europeus modernos - os Estados Nacionais -, a partir de uma cuidadosa análise histórica. Ele argumenta que a formação dos Estados Nacionais europeus, na sequência da fragmentação dos impérios até então existentes, decorreu da necessidade de reunir os recursos necessários ao sucesso nas guerras travadas contra os inimigos externos. Os custos crescentes associados aos empreendimentos bélicos levaram o Estado a abandonar o financiamento de milícias pagas - que elevavam o seu endividamento e revelavam-se arriscadas em razão do comportamento imprevisível dos milicianos 
-, recrutando seus cidadãos para a formação de exércitos. O financiamento da guerra passou a depender, progressivamente, da formação de aparatos burocráticos centralizados capazes de extrair tributos da população em um determinado território. Naturalmente, estes processos - o recrutamento de homens para as Forças Armadas e o pagamento de tributos - não decorriam de ações voluntárias, descansando na capacidade de coerção e regulação, pelo Estado, dos movimentos e atividades em seu território. Os Estados que melhor desempenharam o monopólio do controle e coerção também foram aqueles que melhor organizaram seus Exércitos, sendo os vencedores nas guerras de formação dos Estados Nacionais (Tilly, 1990).

Centeno, tomando como referência o arcabouço analítico desenvolvido por Tilly, busca compreender os processos de formação do Estado Nacional na América Latina. Ao contrário dos Estados europeus, os Estados latino-americanos não atravessaram longos períodos de guerra com os países vizinhos e, ademais, caracterizam-se pela presença de débeis aparatos impositivos, que garantem somente baixos níveis de extração tributária. Os principais conflitos enfrentados pelos Estados latino-americanos no século XIX diziam respeito a disputas regionais internas, e não a ameaças oriundas do exterior. Estes conflitos civis geralmente não eram resolvidos em favor de um ou outro lado, apenas exacerbando o contexto de tensão preexistente internamente. O medo do inimigo interno, ademais, inibiu a formação de uma autoridade central, incluindo aí a capacidade de formação de aparatos burocráticos centralizados. As guerras com os países vizinhos, por sua vez, ocorreram geralmente em períodos que antecederam a formação de qualquer sentido comum de Nação. Nesse contexto, as ameaças externas acabavam por levar à divisão das elites, ao colapso econômico e a ampliação do nível de endividamento (Centeno, 2002).

Na América Latina, não foram constituídos aparatos arrecadatórios centralizados, capazes de garantir a capacidade de extração tributária pelos seus respectivos governos centrais. Adicionalmente, o fato de suas economias dependerem da exportação de commodities (agrícolas ou minerais) para os mercados internacionais inibiu a formação de burocracias extrativas efetivas, em razão de dois fatores centrais: em primeiro lugar, a facilidade em tributar o comércio exterior (particularmente as importações) e em contrair empréstimos externos desestimulou a busca por receitas oriundas de fontes diversas, mesmo no contexto de frequentes crises econômicas. Em segundo lugar, justamente porque as suas economias dependiam das exportações de commodities, as elites econômicas resistiam à tributação de suas atividades. A debilidade das classes governantes vis-à-vis as elites econômicas impediam a imposição de capacidades organizacionais semelhantes às observadas na Europa (Centeno, 1997).

As características apontadas por Centeno, comuns aos países latino-americanos, também se fizeram presentes no Brasil. Nas próximas seções, voltamo-nos para a análise mais detida da trajetória histórica da construção capacidade tributária brasileira, buscando identificar as conjunturas críticas e as disputas políticas que 
levaram à definição de um sistema tributário que, embora tenha permitido a elevação da arrecadação, tornou-se complexo e regressivo.

\section{A ARRECADAÇÃO TRIBUTÁRIA NA AUSÊNCIA DE UM SISTEMA IMPOSITIVO: A TRAJETÓRIA DA TRIBUTAÇÃO DA PRIMEIRA REPÚBLICA AO GOVERNO JOÃO GOULART}

No começo do século XX, o Brasil era um país agroexportador, cuja economia era dependente da exportação de café. Na época, importavam-se virtualmente todos os bens manufaturados consumidos no país. Não por acaso, sua principal fonte de receita encontrava-se nas tarifas sobre o comércio exterior, com ênfase para aquelas que recaíam sobre as importações ${ }^{7}$. Até a década de 30, o imposto sobre as importações representava cerca de $50 \%$ da arrecadação total (Varsano, 1996). A arrecadação tributária, porém, não era responsável pelo financiamento dos grandes empreendimentos da época - como portos e ferrovias -, os quais foram construídos a partir da contração de empréstimos (Melo, 2005).

A Constituição de 1891 manteve, virtualmente, as mesmas fontes de receitas praticadas durante o Império, centradas no comércio exterior, mas modificou a competência para tributar, permitindo às diferentes esferas de governo autonomia na arrecadação de determinados impostos. A coleta de tributos sobre exportações e importações foi dividida entre a União e os estados, que também poderiam criar outros impostos não previstos na Constituição. Essa disposição permitiu a criação, na década de 20, do imposto sobre vendas mercantis e do imposto de renda (IR), ambos de competência da União. O texto constitucional não previa arrecadação própria para os municípios, que dependiam da partilha determinada pelos estados (Varsano, 1996).

Quadro 1 - Constituição de 1891 - Competências Tributárias

\begin{tabular}{|l|l|}
\hline União & $\begin{array}{l}\text { Impostos sobre importação; direitos de entrada, saída e estadia de navios; taxas de selo; } \\
\text { taxas dos correios e telégrafos federais. }\end{array}$ \\
\hline Estados & $\begin{array}{l}\text { Impostos sobre a exportação de mercadorias de sua própria produção (isto é, nas transações } \\
\text { com o exterior e com outros estados); impostos sobre imóveis rurais e urbanos; impostos } \\
\text { sobre a transmissão de propriedade; impostos sobre indústrias e profissões; taxas de selos; } \\
\text { contribuições concernentes aos seus telégrafos e correios. }\end{array}$ \\
\hline
\end{tabular}

Fonte: Elaboração própria com base em Brasil (1891).

Enquanto vigeu a República Velha, não houve espaço para se introduzirem modificações substantivas na base tributária. Os proprietários rurais vetavam qualquer intento de introduzir tributos sobre a propriedade ou sobre suas atividades. Além disso, o baixo nível de urbanização e a reduzida renda da população tornavam marginal a coleta de impostos incidentes sobre as atividades internas e sobre a renda (Oliveira, 2010). 
A baixa capacidade de arrecadação de impostos na época se explica também pela debilidade da burocracia arrecadatória. A Diretoria da Receita Pública, criada em 1909, possuía competência restrita à coleta de impostos internos - sobre o consumo e a renda -, em um contexto no qual a arrecadação se concentrava nos impostos sobre o comércio exterior. A Diretoria possuía uma estrutura de administração tributária herdada do Império, encontrando-se despreparada até mesmo para exercer sua competência de cobrança dos poucos impostos internos. Sua ineficiência também se devia à nomeação de chefes em caráter definitivo, isto é, indemissíveis (Ipea, 2010).

O perfil da base tributária no Brasil só veio a ser modificado a partir da Grande Depressão de 30, quando se registrou queda nas exportações de café e também nas importações, e consequente redução na arrecadação dos tributos sobre comércio exterior. Em 1930, com a chegada de Getúlio Vargas ao poder, inaugurou-se o período nacional desenvolvimentista, caracterizado pela estratégia de industrialização. Diante do novo cenário, marcado pela forte participação do Estado na promoção de investimentos públicos e na indução de investimentos privados, tornava-se necessária a modificação da base de arrecadação tributária brasileira, com maior importância para os impostos internos. Esta mudança foi definida pela Constituição de 1934: os impostos sobre a renda e o consumo, anteriormente criados por lei ordinária, passaram a ser definidos pelo texto constitucional. Os impostos sobre transmissão de propriedade foram separados em causa mortis e inter vivos. Foi instituído o imposto sobre vendas e consignações, que ampliou a base anteriormente tributada pelo imposto sobre vendas mercantis (Oliveira, 1991; Ipea, 2010).

Quadro 2 - Constituição de 1934 - Competências Tributárias

\begin{tabular}{|l|l|}
\hline União & $\begin{array}{l}\text { Imp. importação; imp. consumo; imp. renda; imp. transferência de fundos para } \\
\text { o exterior; imp. "atos emanados do seu Governo, negócios da sua economia e } \\
\text { instrumentos de contratos ou atos regulados por lei federal"; taxas diversas. }\end{array}$ \\
\hline Estados & $\begin{array}{l}\text { Imp. Exportação; imp. vendas e consignações; imp. indústrias e profissões; imp. } \\
\text { propriedade territorial rural; imp. transmissão de propriedade causa mortis e inter vivos; } \\
\text { imp. consumo de combustíveis; imp. "atos emanados do seu governo e negócios da sua } \\
\text { economia ou regulados por lei estadual"; taxas de serviços estaduais. }\end{array}$ \\
\hline Municípios & $\begin{array}{l}\text { Imp. licenças; imp. predial e territorial urbanos; imp. diversões públicas; imp. cedular } \\
\text { sobre a renda de imóveis rurais; taxas sobre os serviços municipais }\end{array}$ \\
\hline
\end{tabular}

Fonte: Elaboração própria com base emBrasil (1934).

A Constituição de 1934 introduziu um novo arranjo de divisão de competências tributárias entre a União e os estados: (i) os estados poderiam criar novos tributos, mas sua arrecadação deveria ser compartilhada com a União e os municípios; (ii) as alíquotas dos impostos sobre as exportações estavam limitadas a 10\%, a fim de estimulá-las; (iii) vedava-se a cobrança de impostos interestaduais ${ }^{8}$ (Ipea, 2010). Vale mencionar ainda que a Constituição definia, pela primeira vez, competências tributárias aos municípios. 
As modificações na base de arrecadação tributária vieram acompanhadas pela criação de uma nova burocracia impositiva, a Direção Geral da Fazenda Nacional (DGFN), criada em 1934. Em comparação à antiga Diretoria da Receita Pública, a nova burocracia representava um avanço, pois passou a contemplar a fiscalização, arrecadação e apoio administrativo em relação à cobrança de todos os impostos federais. O cumprimento da função de fisco, porém, era dificultado pela compartimentalização da DFGN, que se dividia em departamentos que não mantinham diálogo entre si (Departamento de Rendas Internas, de Rendas Aduaneiras e do Imposto de Renda). Como consequência, havia superposição de funções entre os departamentos, o que levava à elevação dos custos e à queda da eficiência (Ipea, 2010).

Interessante notar que as principais disposições em torno da base da arrecadação e da repartição de competências entre as esferas de governo definidas pela Constituição de 1934 permaneceram mesmo após a inauguração do Estado Novo ${ }^{9}$. Como se sabe, o apogeu do projeto varguista ocorreu com a outorga da Constituição de 1937, quando se inaugurou o período ditatorial e se adotou um modelo corporativista de coordenação das relações sociais, com forte centralização na figura do Estado. 0 aparente paradoxo na configuração da repartição das competências tributárias no período respondia aos interesses de Vargas em executar o seu projeto político: mais importante que fortalecer as finanças municipais, as mudanças reduziam o poder dos estados, permitindo ao governo central formatar alianças políticas sem a interposição dos governadores estaduais (Ipea, 2010).

Com o avanço da industrialização e da urbanização, conformavam-se as bases necessárias para o crescimento da arrecadação dos impostos definidos pela Constituição de 1934, os quais permaneceram no texto constitucional de 1937 (Oliveira, 1991). O imposto sobre importações passou a ocupar progressivamente um papel marginal na arrecadação total, cedendo espaço para a participação crescente dos impostos sobre consumo e renda (na esfera federal) e sobre vendas e consignações (no plano estadual) (Varsano, 1996).

Vargas foi deposto em 1945, tendo início o breve período democrático que se estenderia até 1964. Apesar da mudança de regime político e da promulgação de uma nova Constituição, em 1946, não foram introduzidas mudanças significativas na base tributária (Oliveira, 1991). Já no que diz respeito à repartição das competências tributárias entre as esferas de governo, foram introduzidas modificações em favor do fortalecimento das finanças municipais: a Constituição de 1946 concedeu aos municípios a prerrogativa de cobrança do imposto sobre o selo municipal e do imposto sobre indústrias e profissões, antes de competência estadual. Suas finanças também foram favorecidas, formalmente, pela alteração das regras de repartição de receitas entre estados e municípios, em favor dos últimos ${ }^{10}$ (Brasil, 1946).

Em comparação ao período anterior, o texto constitucional limitava a arrecadação própria dos estados. Definiu-se uma alíquota máxima de $5 \%$ nos impostos sobre exportações, com o objetivo de elevar a competitividade dos produtos 
brasileiros no mercado internacional. A cobrança do imposto sobre combustíveis, constitucionalizada, passou para a competência da União (Brasil, 1946).

Quadro 3 - Constituição de 1946 - Competências Tributárias

\begin{tabular}{|l|l|}
\hline União & $\begin{array}{l}\text { Imp. importação; imp. sobre consumo; imp. renda; imp. transferências ao exterior; imp. } \\
\text { negócios de sua economia, atos e instrumentos regulados por lei federal; imp. único } \\
\text { sobre lubrificantes e combustíveis; imp. único sobre energia elétrica; imp. único sobre } \\
\text { minerais; contribuições de melhoria; taxas. }\end{array}$ \\
\hline Estados & $\begin{array}{l}\text { Imp. vendas e consignações; imp. sobre exportação; imp. transmissão de propriedade } \\
\text { causa mortis e inter vivo; imp. propriedade territorial rural; imp. atos regulados por lei } \\
\text { estadual; imp. serviços de sua Justiça e negócios de sua economia; contribuições de } \\
\text { melhoria; taxas. }\end{array}$ \\
\hline Municípios & $\begin{array}{l}\text { Imp. predial e territorial urbano; imp. licença, de indústrias e profissões; imp. diversões } \\
\text { públicas, sobre atos de sua economia ou assuntos de sua competência; contribuições de } \\
\text { melhoria; taxas. }\end{array}$ \\
\hline
\end{tabular}

Fonte: Elaboração própria com base em Brasil (1946).

A partir de então, definiu-se um mecanismo de compartilhamento das receitas entre União, estados e municípios. A União deveria transferir parte da receita oriunda do IUCL e do IR para estados e municípios. Os estados, por sua vez, deveriam repassar aos municípios o excesso de arrecadação do imposto sobre exportações. A partir desse momento, a questão da repartição de receitas - e não somente da competência para coletar impostos - passou a ocupar um lugar central no conflito distributivo entre as esferas de governo. $O$ combate às desigualdades regionais também ganhou relevância inédita: a Constituição de 1946 definia a transferência de receitas para o combate à seca no Nordeste, para a exploração do potencial econômico da bacia do Rio São Francisco e para o plano de valorização da Amazônia (Ipea, 2010, p.337).

Durante as décadas de 40 e 50, a industrialização e a urbanização brasileira se aceleraram, permitindo a consolidação do padrão da arrecadação em favor das receitas provenientes do consumo e dos rendimentos. A aceleração da industrialização na década de 50, calcada nos investimentos públicos, evidenciou a necessidade de ampliação da base tributária e a melhoria no funcionamento da administração fazendária. A arrecadação oriunda da base tributária definida ainda na década de 30 encontrava-se muito aquém das necessidades de investimentos do Estado, em um contexto de crescimento dos gastos públicos (Oliveira, 1991; Varsano, 1996).

Durante o novo governo Vargas (1951-1954), já se discutia a reforma tributária, no âmbito da Comissão Mista Brasil-Estados Unidos. Em 1953, foi formada uma comissão no Congresso para elaboração do projeto que instituiria o Código Tributário. Uma vez finalizado, o documento foi enviado ao presidente e, então, para o Congresso. Não chegou, porém, a ser debatido em plenário, haja vista a multiplicidade de interesses envolvidos. "Mudanças mais profundas na estrutura tributária implicariam colocar em risco o arco de alianças, inclusive interregionais (sic), e desagradar as forças políticas e 
econômicas que sustentavam o governo no pacto que ficou conhecido como Estado de compromisso." (Ipea, 2010, p.342).

Devido à impossibilidade de formação de um consenso em torno da reforma tributária, o país passou a enfrentar desequilíbrios recorrentes nas contas públicas. Este cenário se agravou diante das restrições na disponibilidade de fontes externas de financiamento. O governo Juscelino Kubistchek (1956-1961) implementou o Plano de Metas, voltado para que o impulso à infraestrutura e à industrialização brasileira, tendo como alicerce o investimento público federal, nos limites deste difícil contexto econômico (Oliveira, 1991).

Para dar sustentação a essa nova fase de industrialização, faziam-se necessárias novas fontes de receita. A reforma tributária, embora ventilada, encontrava resistência entre os setores industriais, os prováveis afetados pela introdução de novos impostos. Nesse contexto, o governo JK recorreu a três estratégias centrais, que encontravam menor resistência política: (i) atração de investimentos estrangeiros; (ii) emissão de moeda (o que gerou inflação) (Oliveira, 1991; Varsano, 1996); (iii) criação de fundos com finalidades predeterminadas, aos quais se destinavam impostos e taxas específicas (Lima Júnior 1998). Na ausência de uma reforma tributária que ampliasse a capacidade de arrecadação ${ }^{11}$, as medidas adotadas redundaram no déficit acentuado das contas públicas.

No começo da década de 60 (nos governos Jânio Quadros e João Goulart), o país passou a registrar aceleração da inflação e redução do afluxo de investimentos estrangeiros (Oliveira, 1991). Goulart esforçou-se para elevar a arrecadação, mesmo no contexto de forte instabilidade institucional - que levaria à sua deposição, em 1964. No entanto, não havia espaço para a construção de um consenso em torno da reforma tributária. Por isso, o governo optou por elevar as alíquotas de alguns impostos, inclusive sobre os ganhos de capital, o que encontrou resistência entre os empresários. Para o empresariado, a carga tributária incidia desproporcionalmente sobre o setor produtivo, que se via afetado pela cobrança de impostos cumulativos. Apesar das resistências, em 1963, foi criada a Comissão de Reforma do Ministério da Fazenda, que visava reorganizar a administração fiscal, tornando-a mais moderna e eficiente. Mesmo com o golpe de 31 de março de 1964, que derrubou Goulart e instaurou o Regime Militar, os trabalhos da comissão tiveram prosseguimento (Varsano, 1996). As bases para a sua operação, contudo, haviam se modificado radicalmente.

\section{A ORIGEM DA TRIBUTAÇÃO ELEVADA NO BRASIL: REGIME MILITAR, DESENVOLVIMENTISMO E REFORMA TRIBUTÁRIA}

A mudança de regime político não implicou na ruptura em relação à estratégia de desenvolvimento, sendo mantido o consenso em torno da ISI. Essa estratégia, porém, passou a se assentar em uma nova base de apoio societal: o tripé empresas estatais, capital nacional privado e capital estrangeiro. 
Logo após o golpe de Estado, foi implementado o Plano de Ação Econômica do Governo (PAEG) ${ }^{12}$, no âmbito do qual foi introduzida a reforma tributária. Paradoxalmente, a reforma foi implementada no contexto da emergência ao poder da coalizão que impedia as reformas pretendidas pelos governos democráticos. A longevidade do consenso em torno do desenvolvimentismo criou um cenário favorável para que as demandas em favor da reforma tributária pudessem ser traduzidas na realidade. Naturalmente, a repartição dos custos e benefícios levada adiante se encontrava muito distante daquela almejada pelo governo Goulart: a reforma tributária acompanhou o padrão excludente do modelo desenvolvimentista do Regime Militar.

Entre os anos de 1964 e 1966, os governos militares implementaram uma série de modificações na estrutura tributária, que culminaram na adoção do Código Tributário (1966), vigente até os dias atuais. Foram definidas medidas que visavam reorganizar as contas públicas, combatendo o déficit, ao mesmo tempo em que eram atendidas as demandas dos empresários (Varsano, 1996). Partia-se do diagnóstico segundo o qual as legislações tributárias existentes eram insuficientes para o enfrentamento da inflação; os impostos indiretos e cumulativos inibiam os investimentos produtivos; não havia funcionalidade econômica na cobrança de diversos impostos; e a coordenação tributária entre a União, os estados e os municípios era inexistente (Maciel, 2009). Com a reforma, pela primeira vez, a base tributária foi organizada de acordo com a base econômica (Ipea, 2010). Pretendia-se conferir racionalidade econômica à cobrança de impostos, até então considerados meros instrumentos para elevação da arrecadação.

A reforma tributária implicou na manutenção, criação, substituição e eliminação de diferentes impostos. Estas modificações são elencadas no quadro a seguir:

\section{Quadro 4 - Constituição de 1967 - Modificações na base tributária}

\begin{tabular}{|l|l|}
\hline Impostos mantidos & $\begin{array}{l}\text { Imp. importações; imp. exportações; imp. propriedade rural; imp. renda; imp. } \\
\text { produção, importação, circulação, distribuição ou consumo de combustíveis } \\
\text { e lubrificantes, energia elétrica e minerais; imp. propriedade predial territorial } \\
\text { urbana }\end{array}$ \\
\hline Impostos extintos & $\begin{array}{l}\text { Imp. indústrias e profissões; imp. selo, para todas as esferas; imp. licença; imp. } \\
\text { diversões públicas. }\end{array}$ \\
\hline Impostos substituídos & $\begin{array}{l}\text { Imposto sobre Produtos Industrializados (IPI) e o Imposto sobre Circulação de } \\
\text { Mercadorias (ICM): em substituição aos impostos cumulativos que incidiam } \\
\text { sobre a cadeia produtiva; Imposto sobre Serviços (ISS): em substituição aos } \\
\text { diversos impostos municipais; } \\
\text { Imposto sobre a transmissão de bens imóveis (ITBI): em substituição aos } \\
\text { impostos sobre transmissão de bens imóveis inter vivos e o de causa mortis, } \\
\text { de competência municipal. }\end{array}$ \\
\hline Impostos criados & $\begin{array}{l}\text { Imp. operações financeiras (ISOF); imp. serviços de transportes e } \\
\text { comunicações; imposto único sobre minerais (IUM). }\end{array}$ \\
\hline
\end{tabular}


Pela primeira vez, o Brasil passou a contar, efetivamente, com um sistema tributário, regulamentado pelo Código Tributário. Como resultado, a arrecadação tributária passou de 8,6\% do PIB, em 1962, para 12\% do PIB, em 1965 (Varsano, 1996). O Brasil passou a registrar os mais elevados níveis de arrecadação tributária na América Latina, feito particularmente notável tendo-se em conta que diversos outros países da região também adotavam estratégias desenvolvimentistas. Não se atentou, porém, para o problema da regressividade da estrutura tributária, fato esse agravado pela adoção de um modelo de desenvolvimento concentrador da renda.

Além da modernização do sistema tributário, a reforma também teve como objetivo a centralização da administração tributária, justificada pela necessidade orientar o processo de desenvolvimento (Oliveira, 1991), o que tornava, na prática, estados e municípios dependentes da alocação de recursos por parte da União. Vale mencionar que o texto constitucional atribuía somente à União a competência para criação de novos impostos. Além disso, o ICM, de competência estadual, teria suas alíquotas definidas pela União (Sallum Júnior, 1996).

\section{Quadro 5 - Constituição de 1967 - Competências Tributárias}

\begin{tabular}{|l|l|}
\hline União & $\begin{array}{l}\text { Imp. importação (II); imp. exportação (IE); imp. propriedade territorial rural (ITR); imp. } \\
\text { renda (IR); imp. produtos industrializados (IPI); imp. operações de crédito (ISOF); imp. } \\
\text { serviços de transporte (ISTR) imp. serviçOs de comunicações (ISC); imp. lubrificantes e } \\
\text { combustíveis líquidos ou gasosos (IULC); imp. energia elétrica (IUEE); imp. minerais (IUM). }\end{array}$ \\
\hline Estados & $\begin{array}{l}\text { Imp. transmissão de bens imóveis (ITBI); imp. circulação de mercadorias (ICM); imp. } \\
\text { propriedade de veículos automotores (IPVA). }\end{array}$ \\
\hline Municípios & Imp. propriedade territorial urbana (IPTU); imp. serviços de qualquer natureza (ISS). \\
\hline
\end{tabular}

Fonte: Elaboração própria com base em Brasil (1967)

Além da forte limitação da competência tributária dos estados e dos municípios, as relações entre as diferentes esferas de governo também foram impactadas pela instituição de um sistema de transferências fiscais. Foram criados dois fundos: o Fundo de Participação dos Estados (FPE) e o Fundo de Participação dos Municípios (FPM), compostos por um percentual fixo da arrecadação do IR e do IPI. Foi estabelecido ainda o Fundo Especial (FE), também composto por parte da arrecadação do IR do IPI. Neste caso, porém, o acesso aos recursos do fundo dependia do cumprimento de critérios estabelecidos discricionariamente pelo governo federal, que definia inclusive áreas nas quais os recursos deveriam ser aplicados. Com o passar dos anos, o volume de transferências da União para estados e municípios foi reduzido, ampliando a dependência dos governos subnacionais em relação ao governo central (Sallum Júnior, 1996; Varsano, 1996).

A centralização da arrecadação e da alocação dos recursos se inseria no marco mais amplo da política econômica voltada para a promoção da industrialização substitutiva de importações. Incentivos fiscais - como reduções pontuais do IPI, IR, II e ICM - foram 
amplamente adotados para influenciar as decisões de investimento do setor privado nas áreas consideradas prioritárias (Oliveira, 1991; Sallum Júnior, 1996; Varsano, 1996). A concessão de incentivos fiscais também ocorreu no âmbito das políticas de combate às desigualdades regionais. Nessa seara, o governo militar promoveu a reestruturação da Superintendência do Desenvolvimento do Nordeste (Sudene), existente desde 1959, além de criar a Superintendência do Desenvolvimento da Amazônia (Sudam), estabelecida em 1966 ${ }^{13}$, e da Zona Franca de Manaus, criada em $1967^{14}$ (Maciel, 2009).

A efetividade da arrecadação definida pela nova estrutura tributária dependia da reorganização da burocracia impositiva. Como vimos, a DGFN, criada na década de 30, não cumpria adequadamente a função de fisco. Em 1968, ela foi extinta, sendo substituída pela Secretaria da Receita Federal (SRF). Formou-se uma burocracia profissional, capaz de exercer as diversas atividades relacionadas com o fisco: tributação, arrecadação, fiscalização e provisão de informações econômico-fiscais (Brasil, 20--).

Com a estabilização econômica, criaram-se as condições para a promoção de investimentos públicos em infraestrutura e na indústria, além da atração de investimentos estrangeiros. Durante os governos Artur da Costa e Silva (1967-1969) e Emílio Garrastazu Médici (1969-1974), o Brasil atravessou um período de forte crescimento econômico, conhecido como Milagre Econômico (1967-1973).

O período de aprofundamento do modelo desenvolvimentista, na década de 70, veio acompanhado pela concessão de um grande volume de incentivos fiscais aos setores produtivos, parte integrante da estratégia de direcionamento dos investimentos. Ampliou-se progressivamente o número de setores beneficiados pela redução do IPI, IR, ISOF e II. Parcela significativa dos benefícios concedidos se direcionou aos setores exportadores, em uma tentativa de sustentar a ampliação da produção industrial sem que se gerassem desequilíbrios no balanço de pagamentos (Oliveira, 1991).

A concessão destes benefícios fiscais, porém, só poderia se sustentar enquanto perdurasse a fase ascendente do ciclo econômico. No entanto, em 1974, quando a capacidade de financiamento das empresas deteriorou-se, o governo recorreu a novas reduções do IPI (Oliveira, 1991). Convém assinalar que a concessão generalizada de incentivos fiscais, lado a lado à ampliação da base de incidência do $\operatorname{IR}^{15}$, tornou o sistema tributário brasileiro bastante regressivo (Ipea, 2010).

O fim do período do "Milagre Econômico" revelou os problemas associados às renúncias tributárias em favor do setor produtivo sobre as finanças públicas. Com o passar do tempo, o governo deixou de criar novos incentivos e instituiu novos tributos para manter a arrecadação, em um contexto de arrefecimento da expansão do PIB: as contribuições ao Programa de Integração Social (PIS), ao Programa de Integração Nacional (PIN) e ao Programa de Redistribuição de Terras e de Estímulo à Agropecuária do Norte e Nordeste (Proterra). A adoção destas contribuições sociais acabou por reintroduzir a cumulatividade no sistema tributário brasileiro (Varsano, 1996). 
A criação dessas contribuições viria a tornar o sistema tributário bastante regressivo, somando-se a outras contribuições instituídas para o financiamento da política social, como o Fundo deGarantia por Tempo de Serviço (FGTS) e o Fundo de Previdência e Assistência Social (FPAS). A regressividade da estrutura tributária contribuía para o aumento da concentração de renda que, aliás, vinha se aprofundando como resultado do próprio modelo econômico (Fagnani, 1997).

O modelo de industrialização por substituição de importações encontrou seus limites a partir do segundo choque do petróleo, em 1979. A dívida externa, contraída a juros flutuantes, elevou-se exponencialmente, levando o Brasil a mergulhar em um prolongado período de recessão ou crescimento pífio, que culminou no período hiperinflacionário.

No mesmo período, o país atravessou um longo período de abertura política, que atravessou os governos Geisel (1974-1979) e João Figueiredo (1979-1985). O timing da abertura é importante para compreendermos as mudanças que viriam a ocorrer: por um lado, houve concomitância entre crise econômica e abertura política. Por outro lado, as eleições diretas dos governadores ocorreram já em 1982, enquanto o presidente foi eleito indiretamente três anos mais tarde. A morte de Tancredo Neves e a posse do vice-presidente, José Sarney, contribuíram para elevar o poder de barganha dos governadores frente o presidente, que contava com baixa legitimidade de origem.

Durante o período pré-constituínte, a força dos governadores vis-à-vis o presidente se expressou em sucessivas alterações na legislação que retiravam receitas da União em favor de estados e municípios. A Emenda Constitucional n²3/83, em particular, ampliou os percentuais a serem transferidos para o FPE (12,5\% em 1984 e $14 \%$ a partir de 1985) e para o FPM (13,5\% em 1984 e 16\% a partir de 1985) (Varsano, 1996).

O governo federal, por sua vez, buscou combater o déficit fiscal e a queda da arrecadação recorrendo a modificações pontuais nos tributos vigentes, além da criação de uma nova contribuição social, o Fundo de Investimento Social (FINSOCIAL), em 1982 (Ipea, 2010). Embora tenha se registrado queda no nível de arrecadação ao longo da década de 80, as medidas adotadas permitiram que a diminuição de receitas não fosse muito acentuada (Oliveira, 2010).

O equacionamento da questão fiscal, na forma de modificações da legislação vigente sobre a política tributária, foi deixado para a Assembleia Constituinte. $\mathrm{Na}$ próxima seção, voltamo-nos para a análise das discussões ocorridas nesta arena em torno da reforma tributária, além de abordarmos os legados institucionais sobre o sistema tributário brasileiro.

\section{A AMPLIAÇÃO DA COMPLEXIDADE TRIBUTÁRIA: A CONSTITUIÇÃO DE 1988 E SEUS LEGADOS}

O lento processo de abertura democrática impediu que fossem tratadas mudanças profundas na estrutura tributária. A despeito da crise fiscal, estas mudanças só vieram 
a ser debatidas durante os trabalhos de elaboração da nova Constituição Federal, promulgada em 1988 (doravante CF88). A Assembléia Constituinte se desenrolou no contexto de fortalecimento dos governadores (e também dos deputados, eleitos em 1986) vis-à-vis o Poder Executivo Federal. As principais questões colocadas em debate, na seara das finanças públicas, diziam respeito à descentralização das receitas em favor dos estados e dos municípios - estes promovidos a unidades federativas no texto constitucional.

Durante os trabalhos de elaboração da CF88, as questões tributárias ficaram a cargo da Comissão do Sistema Tributário, Orçamento e Finanças (CSTOF) ${ }^{16}$. No entanto, esta não foi a única comissão a se dedicar a questões orçamentárias. A Comissão de Ordem Social tratou da formação de um orçamento específico para a seguridade social (previdência social, saúde pública e assistência social), que contemplava a destinação das receitas provenientes das contribuições sociais para o seu financiamento.

Vejamos, em primeiro lugar, os trabalhos no âmbito da CSTOF. Ao contrário do que se esperava no momento inicial - quando se imaginava o embate entre progressistas e conservadores -, a Subcomissão do Sistema Tributário teve suas discussões permeadas pela necessidade de fortalecimento do federalismo e de redução das desigualdades regionais, enfatizadas pelos deputados oriundos dos estados da região Nordeste, maioria na comissão. As questões relativas à maior progressividade da estrutura tributária foram relegadas a um plano secundário (Oliveira, 1992).

As preocupações em torno do fortalecimento do federalismo, em busca da reversão da centralização tributária promovida pelo regime militar, expressaram-se nas propostas apresentadas pela Subcomissão do Sistema Tributário, que incluíam a ampliação da base tributária dos estados e das transferências de recursos da União para estados (via FPE) e municípios (via FPM), além da manutenção dos repasses ao $\mathrm{FE}$, voltado para as regiões Norte e Nordeste, com o objetivo de combater as desigualdades regionais (Oliveira, 1992).

Além da ampliação das receitas disponíveis aos entes federativos, os debates no âmbito da Subcomissão do Sistema Tributário foram atravessados pela questão do combate às desigualdades regionais. Essas preocupações não se expressaram na definição da autonomia para arrecadar tributos ${ }^{17}$, o que é explicado pelo fato que os estados mais pobres dispõem de pouca capacidade de extração tributária, dada a limitação do seu parque produtivo. As diferenças regionais acabaram por aflorar durante os debates em torno da repartição das receitas do FPE e do FPM. A subcomissão aprovou uma proposta - não consensual - que previa a destinação dos recursos destes fundos apenas para regiões que possuíssem renda média abaixo da nacional, isto é, Norte, Nordeste e Centro-Oeste (Oliveira, 1992).

A construção do consenso em torno da repartição de recursos entre os estados e os municípios foi deixada para o plenário da CSTOF, que chegou a uma solução parcial. Definiu-se a ampliação da parcela do IR e do IPI destinada ao FPE, cujos recursos estariam disponíveis a todos os estados. No entanto, o estabelecimento de critérios 
para partilha das receitas entre os estados foi deixado para regulamentação por lei complementar. Além disso, os estados mais desenvolvidos passariam a ter acesso a um Fundo de Exportação, financiado por parte da arrecadação do IPI (Oliveira, 1993).

As questões relativas à distribuição do ônus tributário entre os diferentes setores da sociedade não foram objeto de constitucionalização. A seletividade da cobrança do IPI e do ICMS, que poderiam conferir um caráter progressivo à estrutura tributária, foi deixada a cargo das esferas de governo competentes (respectivamente, União e estados). As discussões em torno da concessão de benefícios fiscais, tema central para a compreensão da regressividade da estrutura tributária brasileira, também foi deixada para regulamentação posterior, por lei complementar (Oliveira, 1992).

As questões ligadas à justiça social, relegadas a um espaço marginal nos debates da CSTOF, ganharam destaque na Comissão da Ordem Social. Esta comissão tratou da universalização do acesso aos direitos sociais ${ }^{18}$, o que levou a CF88 a ser conhecida como a "Constituição Cidadã". Para tanto, demandava-se o aumento dos gastos públicos. A comissão defendeu que as receitas provenientes do FINSOCIAL - disputadas também pela CSTOF - e de outras contribuições sociais a serem instauradas fossem destinados ao Orçamento da Seguridade Social (OSS). Seu propósito exclusivo seria o financiamento da previdência, da assistência social e da saúde pública, assegurando o acesso aos direitos sociais consagrados no texto constitucional (Varsano, 1996).

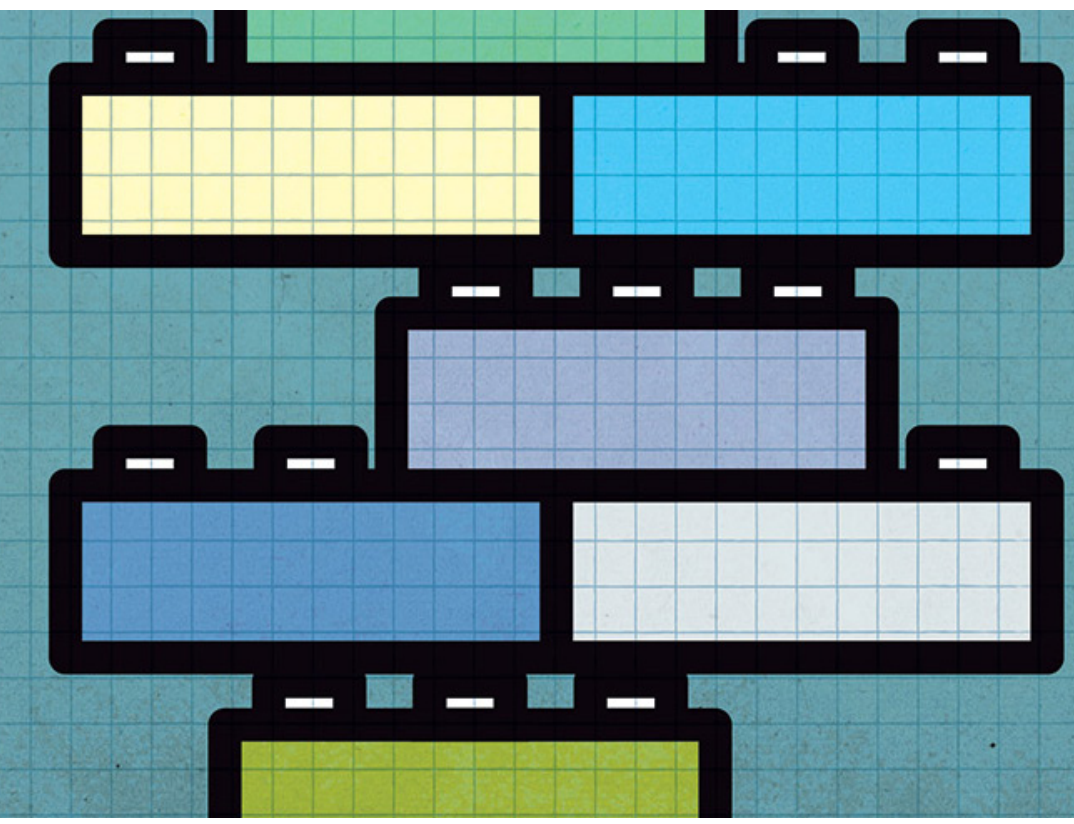


Ao final dos trabalhos, as recomendações das diversas comissões foram submetidas à Comissão de Sistematização, responsável por consolidar os trabalhos ocorridos ao longo da constituinte. Esta comissão definiu que a receita proveniente da arrecadação do FINSOCIAL ${ }^{19}$ e de outras contribuições sociais a serem instituídas após a promulgação da CF88 seria destinado ao OSS. A Comissão de Sistematização aprovou algumas alterações na proposta originalmente apresentada pela CSTOF, incluindo a previsão de criação do imposto sobre grandes fortunas (IGF), a ser definido por lei complementar ${ }^{20}$ e a inclusão dos estados da região Centro-Oeste entre os destinatários dos recursos do FE.

Ao final dos trabalhos da Assembléia Constituinte, foram promovidas mudanças importantes na repartição das competências tributárias entre União, estados e municípios. A base tributária, porém, sofreu poucas alterações significativas, como pode ser visto no Quadro 6.

\section{Quadro 6 - Constituição de 1988 - Competências Tributárias}

\begin{tabular}{|l|l|}
\hline União & $\begin{array}{l}\text { Imp. importação (II); imp. exportação (IE); imp. renda (IRPF e IRPJ); imp. produtos } \\
\text { industrializados (IPI); imp. operaçôes de crédito, câmbio e seguro, ou relativas a títulos } \\
\text { ou valores mobiliários (IOF); imp. propriedade territorial rural (ITR); imp. grandes fortunas } \\
\text { (IGF). }\end{array}$ \\
\hline Estados & $\begin{array}{l}\text { Imp. transmissão causa mortis ou doação (ITCD); imp. circulação de mercadorias e serviço } \\
\text { (ICMS); imp. propriedade de veículos automotores (IPVA). }\end{array}$ \\
\hline Municípios & $\begin{array}{l}\text { Imp. propriedade predial e territorial urbana (IPTU); imp. transmissão inter vivos (ITBI); } \\
\text { imp. serviços de qualquer natureza (ISS); imp. vendas a varejo de combustíveis líquidos e } \\
\text { gasosos, exceto óleo diesel'1 (IVVC). }\end{array}$ \\
\hline
\end{tabular}

Fonte: Elaboração própria com base em Brasil (1988).

Em síntese, a CF88 produziu três impactos importantes sobre as finanças públicas: (i) a desconcentração dos tributos em favor dos estados e municípios, com ênfase para a importância adquirida pelo ICMS; (ii) a elevação das transferências da União para estados e municípios; (iii) a introdução de um capítulo sobre seguridade social, que assegurava como fontes de financiamento as receitas das contribuições sociais. Estas, ao contrário dos impostos, não se sujeitam ao compartilhamento com os estados.

A CF88 gerou um desequilíbrio: descentralizou as receitas, em favor de estados e municípios, mas manteve os encargos nas mãos da União-ainda que temporariamente. Além disso, a União teve suas despesas ampliadas pela universalização do acesso à seguridade social (Varsano, 1996), definida no momento em que o Brasil atravessava uma profunda crise estagflacionária (Azevedo\& Melo, 1997). A Carta Constitucional permitiu, ademais, que o OSS recebesse uma fatia expressiva da arrecadação: já em 1992, as receitas oriundas das contribuições sociais correspondiam a mais da metade do orçamento total (Sola, 1995).

Esse desequilíbrio é fator explicativo para as ações promovidas pelos governos federais na década de 90 , dentre as quais se inclui o aumento de alíquotas e a ênfase dada à arrecadação de contribuições sociais, de incidência cumulativa, o que conduziu 
ao aumento continuado da arrecadação tributária. Estas mudanças, embora gerassem efeitos deletérios sobre a eficiência da atividade econômica e sobre o caráter já regressivo da estrutura tributária, foram consideradas necessárias para que o Executivo Federal pudesse enfrentar seus déficits fiscais. Cabe destacar ainda a aprovação do Fundo Social de Emergência (FSE) - posteriormente denominado Desvinculação das Receitas da União (DRU) -, no governo Itamar Franco, que permitiu à União alocar livremente $20 \%$ das receitas oriundas das contribuições sociais, elevando os incentivos para que o governo federal aumentasse a arrecadação destes tributos (Afonso \& Serra, 2007).

Além dos problemas relacionados à crise fiscal, deve-se salientar também o movimento contraditório observado desde a eleição de Fernando Collor e a adoção de reformas estruturais de orientação neoliberal: a ampliação da provisão de serviços públicos pelo Estado, consagrada pela CF88, foi seguida, imediatamente, pela adoção de uma estratégia de encolhimento do Estado. Passou a ocorrer, assim, uma disjunção entre a estratégia econômica e os propósitos das instituições tributárias. No bojo das reformas estruturais, incluía-se uma proposta de desoneração do setor produtivo, com a discussão de uma reforma tributária, voltada para retirar os "excessos" da CF88 apontados pela coalizão neoliberal.

Emendas constitucionais em diversas esferas das políticas públicas foram aprovadas durante a década de 90. No entanto, a CF88 gerou um efeito de 'dependência da trajetória' sobre o sistema tributário. O texto constitucional moldou as preferências dos múltiplos atores envolvidos na questão tributária, inviabilizando sua reforma (Melo, 2005). Como consequência, manteve-se a complexidade da estrutura tributária, dependente, em grande medida, da arrecadação de tributos com incidência "em cascata" (as contribuições sociais). Nesse sentido, o destaque adquirido pelas contribuições sociais na arrecadação total acentuou o caráter regressivo do sistema tributário brasileiro. Ademais, o desvio de suas receitas para áreas alheias à seguridade social- sobretudo para os serviços da dívida pública, que cresceu durante a década de 90 - impediu que seus recursos pudessem ser empregados adequadamente na universalização do acesso aos direitos sociais definidos no texto constitucional.

\section{COMENTÁRIOS FINAIS}

Durante a Nova República, tornou-se lugar comum dirigir críticas ao sistema tributário brasileiro. A elevada carga impositiva, o grande número de tributos, a multiplicidade de isenções fiscais e o caráter regressivo do sistema impositivo têm sido objeto de críticas por diferentes setores da sociedade civil - desde o empresariado até as entidades sindicais -, embora não coincidam, necessariamente, a respeito quais características consideradas deletérias devam ser combatidas.

Neste artigo, buscamos entender porque o sistema tributário brasileiro apresenta as características hoje observadas. Para tanto, recorremos a uma análise da trajetória 
histórica de definição de regras e de mudanças institucionais em torno da tributação no Brasil. A emergência de coalizões desenvolvimentistas abriu espaço para a formação de um consenso em torno da ampliação da capacidade tributária do Estado, essencial para a promoção de uma agenda centrada na ampliação dos investimentos públicos e da industrialização. O conflito distributivo - os interesses dos atores participantes destas coalizões e, durante o Regime Militar, a exclusão das camadas populares da coalizão de governo - também importa para a compreensão de por que a ampliação da carga tributária veio acompanhada pela maior complexidade do sistema impositivo e pela sua regressividade.

Como se sabe, o consenso em torno do desenvolvimentismo esteve vigente entre as décadas de 30 e 80 . No entanto, as coalizões desenvolvimentistas se configuraram de modo bastante distinto ao longo das décadas. Nesse sentido, embora a necessidade de ampliação da arrecadação se tornasse patente com o avanço do processo de industrialização até meados do século XX, não havia espaço para a construção de um consenso político em torno da repartição dos custos da incidência da tributação sobre os diferentes setores da sociedade. A oposição de grupos poderosos - proprietários rurais e empresários industriais - obstaculizou os intentos de se instituir uma reforma que permitisse a ampliação da arrecadação, o que contribuiu para tornar o modelo de industrialização do período dependente da contração de empréstimos e da emissão de moeda, com efeitos deletérios sobre o nível de endividamento, o balanço de pagamentos e a inflação.
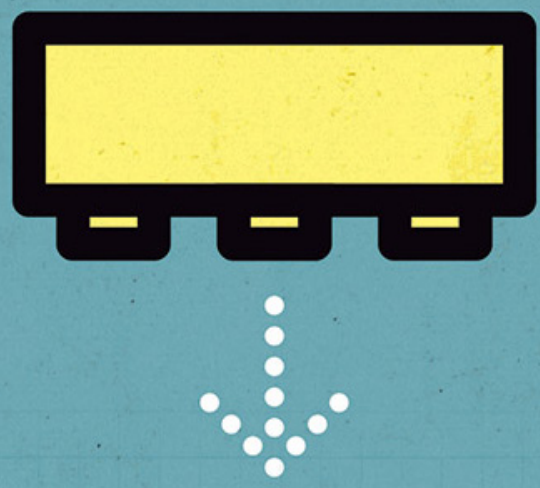
Vale ressaltar que a própria elite industrial beneficiada pelas políticas desenvolvimentistas rechaçava a ampliação da tributação dos seus rendimentos, de forma que apenas com a mudança do regime político tornou-se possível estabelecer um sistema tributário dotado de racionalidade econômica. Com a mudança no regime político - Golpe Militar e emergência de um regime autoritário -, abriu-se uma conjuntura crítica favorável a um consenso em torno do estabelecimento de um sistema tributário dotado de maior racionalidade e eficiência, bem como da criação de burocracias públicas mais efetivas. A reforma tributária, aprovada em 1966, definiu, pela primeira vez, um conjunto de regras sistematizadas a respeito da cobrança de tributos. Tratavase de um sistema tributário considerado funcional à estratégia de promoção da industrialização do país. No entanto, o consenso em torno da reforma, que permitiu a ampliação da capacidade de extração de tributos, foi possível em razão da exclusão dos setores populares do processo decisório, o que foi determinante para a definição do sistema tributário tenha ocorrido sem atenção à questão da progressividade.

A incidência regressiva dos tributos se acentuou na década seguinte. Atendendo às demandas empresariais por isenções fiscais - no contexto do programa de incentivo às exportações de bens manufaturados -, os governos militares buscaram elevar a arrecadação por meio da introdução de contribuições sociais, de incidência cumulativa. A concessão de isenções fiscais e a introdução de contribuições sociais foram determinantes, ademais, para tornarem o sistema tributário complexo, revertendo a simplificação da cobrança de tributos que havia sido instituída com a aprovação do Código Tributário em 1966.

Na década de 80 , a crise econômica e a transição à democracia trouxeram a questão fiscal novamente para o centro das discussões. As mudanças no sistema impositivo, contudo, foram objeto de decisão política somente no âmbito da Assembleia Constituinte, já ao final da década. Novamente, é o estabelecimento de um novo texto constitucional, no marco da conjuntura crítica aberta pela mudança do regime político, que permite a definição de regras que possibilitaram a ampliação da capacidade tributária. Naquela arena, particularmente no âmbito das deliberações da CSTOF, privilegiou-se o equacionamento do conflito distributivo entre as esferas de governo, concedendo-se pouca atenção ao combate à regressividade do sistema tributário brasileiro.

A necessidade de combate às profundas desigualdades sociais no Brasil foi objeto da Comissão de Ordem Social, que buscou assegurar receitas que garantissem o financiamento da universalização do acesso à saúde pública e à seguridade social, além de fortalecer a assistência social. Paradoxalmente, as receitas para tanto adviriam da vinculação da arrecadação de contribuições sociais, de incidência regressiva. O propósito das contribuições sociais - o financiamento da seguridade social - foi, ademais, parcialmente revogado com a aprovação da desvinculação de suas receitas na década de 90 , o que permitiu à União a alocação discricionária de $20 \%$ da receita oriunda destes tributos. Além disso, cumpre salientar que as contribuições sociais 
têm incidência "em cascata", contribuindo para ampliar a complexidade do sistema tributário brasileiro.

Vale mencionar também que as mudanças introduzidas no texto constitucional de 1988 não tinham como objetivo precípuo a ampliação da arrecadação, mas a sua distribuição entre estados e municípios, visando, ao mesmo tempo, reduzir o peso adquirido pela União durante o Regime Militar e combater as desigualdades regionais. No entanto, essas mudanças conferiram maior importância às contribuições sociais no contexto da arrecadação tributária. A multiplicidade de tributos previstos na Constituição de 1988 permitiu aos governos da Nova República lançarem mão de mudanças incrementais e recorrentes nas alíquotas e isenções tributárias (Maciel, 2019), permitindo o aumento da arrecadação e a acomodação de interesses no bojo do conflito distributivo.

\footnotetext{
Notas

${ }^{1}$ A Argentina é o outro país latino-americano onde a relação tributação/PIB se situa acima de 30\%. (CEPAL, 2016).

${ }^{2}$ Vale mencionar que Levi (1988) parte do pressuposto que os governantes buscam maximizar a extração tributária.

${ }^{3}$ Nosso objetivo é discutir a trajetória de construção de instituições que permitiram a ampliação da capacidade tributária no Brasil. Por isso, não focalizaremos, neste artigo, as disputas políticas em torno das propostas de reforma tributária apresentadas durante a Nova República - um objeto de pesquisa importante, mas distinto daquele aqui proposto.

${ }^{4}$ Para uma discussão mais aprofundada sobre as mudanças implementadas, ver: Maciel (2019).

${ }^{5}$ Agenda que inclui política macroeconômica, industrial, de ciência, tecnologia e inovação (CT\&l), de educação e sociais (Boschi, 2012, p. 4).

${ }^{6}$ É verdade que níveis elevados de arrecadação não levam, necessariamente, à maior efetividade das políticas públicas. O inverso, sim, é verdadeiro: Estados com baixa capacidade de extração tributária dificilmente poderão prover políticas públicas adequadas às suas sociedades, particularmente aquelas associadas ao investimento produtivo e ao bem-estar social.

${ }^{7}$ Além dos tributos incidentes sobre o comércio exterior, também existiam impostos sobre a propriedade, sobre as transações internas e sobre a produção. Sua arrecadação, em um país com reduzido nível de urbanização e industrialização, não ocupava lugar proeminente no total de tributos arrecadados.

${ }^{8}$ Mantidos, porém, na prática.

${ }^{9}$ Durante a década de 40, somente alterações pontuais foram introduzidas: a criação do imposto único sobre combustíveis e lubrificantes (IUCL), de competência da União, além de alterações na estrutura de cobrança do IR. As receitas oriundas do IUCL eram sujeitas à transferência para o Fundo Rodoviário dos Estados e Municípios. Trata-se do primeiro arranjo histórico de vinculação nas transferências da União para as unidades subnacionais (Ipea, 2010).

${ }^{10}$ Apesar desses esforços, diversos obstáculos impediram o real fortalecimento das finanças municipais (Ver:Varsano, 1996, p.06).

${ }^{11}$ As modificações na base tributária foram somente pontuais, com a criação de novos impostos e reajustes de alíquotas.

${ }^{12}$ O PAEG reunia um conjunto de medidas contracionistas, voltadas para o enfrentamento da inflação e dos desequilíbrios das contas públicas, dentre as quais se destacam os cortes de gastos públicos, a reforma financeira e do mercado de capitais e a reforma tributária.

${ }^{13}$ Dentre as medidas adotadas, encontravam-se o estabelecimento de fundos para o financiamento regional e a isenção do recolhimento do IRPJ das empresas que se instalassem nas regiões de competência da Sudam e da Sudene (Maciel, 2009).
} 


\footnotetext{
${ }^{14}$ A criação da Zona Franca de Manaus objetivava desenvolver a Amazônia Ocidental, através da concessão de benefícios tributários vigentes por trinta anos. Para atrair indústrias para o local, o governo federal concedeu isenção ou redução do pagamento do IPI, II, IRPJ e do ICM (Maciel, 2009).

${ }^{15}$ Em 1966, somente aqueles que percebessem menos que dez salários mínimos mensais eram isentos do pagamento do IRPF. Apenas três anos mais tarde, a faixa de isenção havia se retraído para dois salários mínimos (Ipea, 2010).

${ }^{16}$ Antes mesmo da instalação da constituinte, diversas propostas de reforma tributária foram apresentadas (ver: Oliveira, 1992).

17 Os deputados que compunham subcomissão optaram pela cobrança do ICMS na produção (concentrada em poucas localidades), em vez do consumo.

${ }^{18}$ Por meio da ampliação da assistência social e da universalização do acesso à saúde pública e à previdência social.

${ }^{19}$ Em de 1991, foi substituída pela Contribuição para o Financiamento da Seguridade Social (COFINS).

${ }^{20}$ A regulamentação do IGF permanece pendente até os dias atuais.

${ }^{21}$ Extinto em 1993.
}

\section{Referências}

AFONSO, J. R.; SERRA, J. Tributação, seguridade e coesão social no Brasil. Serie Políticas Sociales n. 133, CEPAL, 2007. Disponível em: https://bit.ly/2TDP64F. Acesso em: 02.07.2017.

ARRETCHE, M. Quem taxa e quem gasta: a barganha federativa na federação brasileira. Revista de Sociologia Política, n.24, pp.69-85, 2005.

AZEVEDO, S.;MELO, M.A. A política da reforma tributária: federalismo e mudança constitucional. Revista Brasileira de Ciências Sociais, v.12, n. 35, pp.75-99, 1997.

BOSCHI,R. Desenvolvimento, Pactos Políticos e Re-industrialização: desafios para o Brasil. In9 FÓRUM DE ECONOMIA DA FGV, São Paulo, 2012.

BOSCHI, R.; GAITÁN, F. A recuperação do papel do Estado no capitalismo globalizado. In: GOMIDE, A.; BOSCHI, R. (orgs.). Capacidades Estatais em Países Emergentes: o Brasil em perspectiva comparada. Brasília: IPEA, 2016.

BRASIL. Constituição da República dos Estados Unidos do Brasil. Brasília: Presidência da República, 1891.

BRASIL. Constituição da República dos Estados Unidos do Brasil. Brasília: Presidência da República, 1934.

BRASIL. Constituição dos Estados Unidos do Brasil. Brasília: Presidência da República, 1946.

BRASIL. Constituição da República Federativa do Brasil. Brasília: Presidência da República, 1967.

BRASIL. Constituição da República Federativa do Brasil. Brasília, DF: Senado, 1988.

BRASIL. Secretaria da Receita Federal. Memória da Receita Federal: Administração Fazendária, 20. Disponível em: https://bit.ly/2YJbvmF. Acesso em: 02 abr. 2019.

CENTENO, M. Blood and debt: war and taxation in nineteenth century Latin America. American Journal of Sociology, v.102, n.06, pp.1565-1605, 1997.

CENTENO, M. Blood and Debt: war and the nation-state in Latin America. University Park: The Pennsylvania State University, 2002.

CEPAL. Estadísticas e Indicadores, 2016. Disponível em: https://bit.ly/1WcHe86. Acesso em: 02 abr. 2018. 
CROUCH, C.; FARRELL, H. Breaking the path of institutional development? Alternatives to the new determinism. MPIfG Discussion Paper No. 02, 2002. Disponível em http://www.mpifg.de/ pu/mpifg_dp/dp02-5.pdf. Acesso em: 30 abr. 2018.

ENRÍQUEZ, E.; CENTENO, M. State capacity: utilization, durability, and the role of wealth vs. history. RIMCIS - International and Multidisciplinary Journal of Social Sciences, v.01, n.02, pp.130162, 2012.

FADIÑO, P.; KERSTENETZKY, C. O paradoxo constitucional brasileiro: direitos sociais sob tributação regressiva. Revista de Economia Política, v.39, n.02, pp.306-327, 2019.

FAGNANI, E. Política social e pactos conservadores no Brasil: 1964/92. Economia e Sociedade, n.08, pp.183-238, 1997.

GEDDES, B. Politician's dilemma: building state capacity in Latin America. Berkeley: University of California Press, 1994.

GOMIDE, A. Capacidades estatais para políticas públicas em países emergentes: (des)vantagens comparativas do Brasil. In: GOMIDE, A.; BOSCHI, R. (orgs.). Capacidades Estatais em Países Emergentes: o Brasil em perspectiva comparada. Brasília, IPEA, 2016.

IBGE. Estatísticas do Século XX. Disponível em https://bit.ly/1lwf3sH. Acesso em: 04 abr. 2019.

IPEA. Estado, Instituições e Democracia: desenvolvimento. Livro 09, v.03.Brasília: IPEA, 2010.

LEVI, M. Of Rule and Revenue. Berkeley and Los Angeles: University of California Press, 1989.

LIMA JÚNIOR, O. As reformas administrativas no Brasil: modelos, sucessos e fracassos. Revista do Serviço Público, v.49, n.02, pp.05-31, 1998.

MACIEL, M. Dependência de trajetória nos incentivos fiscais: fragmentação do empresariado na reforma tributária. 2009. 127 f. Dissertação (Mestrado em Ciência Política) -Instituto Universitário de Pesquisas do Rio de Janeiro, UCAM, Rio de Janeiro.

MACIEL, M. Paradigmas e progressividade na política tributária dos Estados Unidos e do Brasil. 2019. 290 f. Tese (Doutorado em Ciência Política) - Instituto de Estudos Sociais e Políticos, UERJ, Rio de Janeiro.

MAHONEY, J. Path Dependency in Historical Sociology. Theory and Society, v.29, n.04, pp.507$548,2000$.

MAHONEY, J.; THELEN, K. A theory of gradual institutional change. In: MAHONEY, J.; THELEN, K. (eds.). Explaining institutional change: ambiguity, agency and power. Cambridge: Cambridge University Press, 2010.

MANCUSO, W.; GONÇALVES, M.; MENCARINI, F. Colcha de retalhos: a política de concessão de benefícios tributários ao empresariado no Brasil (1988-2006). In: MANCUSO, W.; LEOPOLDI, M.A.; IGLECIAS, W.(org.). Estado, empresariado e desenvolvimento no Brasil. São Paulo: Ed. de Cultura, 2010.

MELO, M. A. O leviatã brasileiro e a esfinge argentina: os determinantes institucionais da política tributária. Revista Brasileira de Ciências Sociais, v.20, n.58, pp.91-128, 2005.

OLIVEIRA, F. A reforma tributária de 1966 e a acumulação de capital no Brasil. Belo Horizonte: Oficina de Livros, 1991.

OLIVEIRA, F. A evolução da estrutura tributária e do fisco brasileiro: 1889-2009. Texto para Discussão No. 1469, Brasília,Texto para Discussão IPEA, 2010. Disponível em: https://bit. ly/2ZXPLAd. Acesso em: 20 mai. 2018.

PIERSON, P. Politics in Time. History, Institutions and Social Analysis. Princeton \& Oxford: Princeton University Press, 2005. 
POCHMANN, M. O mito da tributação elevada no Brasil. Folha de São Paulo, 2008. Disponível em: https://bit.ly/30Ctk3l. Acesso em: 30 mar. 2016.

SALLUM JÚNIOR, B. Federação, autoritarismo e democratização. Tempo Social - Revista de Sociologia da USP, v. 8, n. 2, pp. 27-52, 1996.

SKOCPOL, T. Bringing the state back in: strategies of analysis in current research. In: EVANS, P; RUESCHEMEYER, D.; SKOCPOL, T.(eds.). Bringing the state back in. New York, Cambridge University Press, 1985.

SOLA, L. Estado, regime fiscal e ordem monetária: qual Estado? Revista Brasileira de Ciências Sociais, n. 27, 1995.

TILLY, C. Coercion, Capital, and European States: AD 990-1990. Cambridge: Basil Blackwell, 1990.

VARSANO, R. A evolução do sistema tributário brasileiro ao longo do século: anotações e reflexões para futuras reformas. Texto para Discussão No. 405, Rio de Janeiro, Texto para Discussão IPEA, 1996. Disponível em: https://bit.ly/2H2x4Um. Acesso em: 04 mai. 2018. 